\title{
Pragmatics of Political News Reports Worthiness
}

\author{
Fareed H. Al-Hindawi ${ }^{1}$ \& Hani K. Al-Ebadi ${ }^{2}$ \\ ${ }^{1}$ Dept. of English, College of Education for Humanities, Babylon University, Babylon, Iraq \\ ${ }^{2}$ Dept. of English, College of Education for Humanities, Thi-Qar University, Thi-Qar, Iraq \\ Correspondence: Hani K. Al-Ebadi, College of Education for Humanities, Thi-Qar University, Dept. of English, \\ Thi-Qar, Iraq. E-mail: hanialebadi700@gmail.com
}

Received: January 18, 2017 Accepted: March 2, 2017 Online Published: July 15, 2017

doi:10.5539/ijel.v7n4p113 URL: http://doi.org/10.5539/ijel.v7n4p113

\begin{abstract}
With the numerousness of political events and the competition among news media channels, news manufacturing becomes highly weighty to attract audience's attention aiming at changing their minds. As such, news reporters tend to pick out certain events that can be viewed as newsworthy. However, news manufacturing turns to be the reporters' main interest and the various ways used to fulfill this purpose fall into their primary tasks. Among these ways, pragmatic mechanisms of language stand as the most appropriate means to create such newsworthiness. Thus, this study has set itself the task to be after these pragmatic mechanisms as employed by CNN reporters in their attempts to initiate, construct and maximize newsworthiness of the events in question. The findings attained at by this study fully verify some of its hypotheses and partially vindicate other ones.
\end{abstract}

Keywords: deixis, modality, newsworthiness, pragmatics and presupposition

\section{Introduction}

Generally, news reporters pay considerable attention to manufacturing newsworthiness of the events that attract audience and influence their minds. This prompts news reporters to look for efficient mechanisms that fulfill this purpose. In this regard, language pragmatic mechanisms (henceforth PMs) seem to be a sufficiently effective apparatus. This issue represents a stimulus for this study to investigate such PMs as used by CNN reporters to initiate, construct and maximize the newsworthiness of the events in political news reports (henceforth PNRs). Thus, this study aims at (1) finding out these PMs in such reports, (2) pinpointing out the most worthy news values (henceforth NVs) created by PMs in PNRs, (3) figuring out the most frequent PMs employed by CNN reporters to create newsworthiness, and (4) developing a model for analyzing the newsworthiness of PNRs. In connection with those aims, it hypothesizes that: (1) PMs are the efficient tools of reporters to create newsworthiness, (2) not all NVs receive equal significance by CNN reporters to create newsworthiness of political events, (3) CNN reporters rely mainly on presuppositions in the headline stage (henceforth HS) to initiate newsworthiness, (4) deixis and modality are preferable PMs to construct newsworthiness in the lead stage (henceforth LS), and (5) all the PMs of presupposition, modality and deixis are utilized in the development stage (henceforth DS) to construct and maximize such newsworthiness, and (6) the most frequent PMs in the HS, LS, and DS are presupposition, deixis and modality respectively.

\section{Literature Review}

\subsection{News}

The general definition of news reads as the details or information about a happening that interests a certain community or has an impact on the lives of its members. Because of this relationship between news and the targeted community, news media attracts a large number of audience, and hence, is referred to as 'mass media' (Reah, 2002, p. 1).

\subsection{News Discourse}

Kress (1989, p. 7) defines discourse as "systematically organized sets of statements which give expression to the meanings and values of an institution". Worded differently, it constructs reality in terms of re-forcing, reinforcing and implementing the human experience and shapes the world in which interactants live (ibid). Al-Ebadi (2012, p. 2) points out that "since communication exists among interlocutors, it is inevitably influenced by factors related to them such as their attitudes, ideas, and social status and so on". This comes in line with 
Fowler's (1991, p. 66) recent view that discourse is a means of constituting knowledge as well as limiting the ways in which we talk about things. In this regard, Al-Duleimi \& Al-Ebadi (2016, pp. 63-64) argue that controlling others' minds is essentially the function of discourse. Regarding news discourse, it is evidently never value-free but a reflection of values. Thus, language appears as an effective means of expressing these values. For instance, news reporters' different opinions can be signaled by the stylistic choices, as van Dijk (1991, p. 209) claims, carrying differing social implications from other available choices (Bell, 1997, p. 240). Participants in news articles personify the discourse and the attributes ascribed to them reflect the knowledge produced by the discourse. In accordance with the definition of news (See 2 above), the details of a happening cannot be independent of their producers and receivers as well.

\subsection{Newsworthiness}

On the basis of what has been just mentioned in (2.2 above), news discourse is produced with some degree of subjective intervention. This assures the existence of a certain viewpoint, attitude, angle of vision or authorial interests that might determine news reports wordings (Fowler, 1977, p. 76). Thus, such an intervention cannot be a haphazard endeavor, but is carefully aimed, planned and done. As for news discourse, its carefully planned targets achieve the newsworthiness of events. Intervening subjectively (or newsworthiness) in news discourse is represented by what is known as NVs. NVs are the elements that judge an event more newsworthy than others. More clearly, they stand as the criteria which can be applied to determine what is news and what is not (van Dijk, 1988, p. 119; Bell, 1991, p. 155; Richardson, 2007, p. 91; Cotter, 2010, p. 68). Thus, as viewed by this study, a variety of NVs are expected to be invested by CNN news reporters in order to broadcast their news as worthy as possible. In this regard, Bednarek \& Caple's (2012, p.42) model of NVs is adopted here to analyze the collected data as will be explained in the following section. This model involves negativity, impact, timeliness and proximity.

\subsubsection{Negativity}

This value refers to the offensive occurrences such as disasters, wars damage and so forth. These occurrences give news the property of newsworthiness (Bell, 1991, p. 156; Conboy, 2002, p. 174). As such, it plays an important role to categorize news as negative "destabilizing" versus positive "stabilizing" (Feez et al., 2008, p. 72; Bednarek \& Caple, 2012, p. 42).

\subsubsection{Impact}

It is agreed that important events do not pass without influencing audience but the degree of influence may be ranked piecemeal. Greater influential events upon audience are more newsworthy than lesser ones (Van Dijk, 1988, p. 122; Bell, 1991, p.158; Bednarek \& Caple, 2010, p. 42).

\subsubsection{Timeliness}

Another factor of judging events as newsworthy is the time of their occurrences. Worded differently, the time of the happening bestows on it the property of newsworthiness. In this respect, Bell (1991, p. 156) mentions that recent events are newsworthy when they have just taken place. Moreover, it is also valuable when it is still ongoing or will happen in near future (Bednarek \& Caple, 2012, p. 42).

\subsubsection{Proximity}

The nearness of the happenings also plays a role to characterize a certain event as newsworthy. This value represents the cultural and/or geographical nearness of the event. Thus, priority is given to the locality of that event. When an event is local, it becomes more worthy than distant ones which are delivered cognitively (Bell, 1991, p. 157; Cotter, 2010, p. 49; Bednarek \& Caple, 2012, p. 44).

To sum up, these NVs, among several others, represent the standards to judge whether an event is newsworthy or not. In other words, audience gives priority to events involving such standards or values. Thus, they will be utilized to figure out the newsworthiness that CNN news reporters create and rely on to broadcast their news.

\subsection{Newsworthiness as a Discursive Process}

Generally speaking, newsworthiness is tackled by two broad perspectives including cognitive and discursive ones. The former conceptualizes newsworthiness as beliefs, inter-subjective mental categories that people apply to qualities/aspects that make something newsworthy. Such beliefs about newsworthiness may at times vary according to the individuals concerned. Put differently, every journalist and every editor will have a different interpretation of what is newsworthy because of its subjective process (Fowler, 1991, p. 17; Rau, 2010, p. 14; Bednarek \& Caple, 2012, p. 44). 
The latter perspective conceptualizes newsworthiness in terms of how it is construed through discourse, precisely PMs in this work. As such, it is not inherent in events but established through language (ibid., pp. 45). In other words, the focus here is not on the nature of news events, but rather on how such events are mediated through language (ibid.).

\subsection{News Report Structure}

The process of news editing follows a particular structure. Therefore, news stories or reports encompass three parts: headline, lead and development (ibid., p. 96). They work together to present an event as newsworthy. However, each part has certain characteristics as well as functions. In this work, these parts will be referred to as stages of news reports manufacturing as illustrated in the following sub-sections.

\subsubsection{Headline (Initiating)}

The HS is the first part of PNRs which should be derived from the lead and development although it works independently. More importantly, it performs a variety of functions such as summarizing the event, attracting audience's attention and providing stance towards the report. Moreover, the main function of this part is initiating newsworthiness of the event (ibid.).

\subsubsection{Lead (Constructing)}

The second part of the PNRs which works simultaneously with HS as a beginning of the report is known as the lead stage (henceforth LS). As with the HS, it fulfills a variety of tasks such as constructing newsworthiness of the event in question and increasing audience's attraction. Besides, it describes the newsworthiness aspects such as who, when and where. In addition, this part may talk about more than one event, embed background through a complex discourse structure (Cotter, 2010, p. 162; Bednarek \& Caple, 2012, p. 97).

\subsubsection{Development (Maximizing)}

The development stage (DS) represents the third part of the PNR. As the title suggests, it develops the main points raised in the previous parts. Thus, it contains different types of information covering background and context as well as features attribution of information (ibid., p. 98).

In conclusion, it is worthy to remark here again that this work is after the PMs utilized by CNN news reporters to create newsworthiness in these three parts of the report. Besides, it traces how these mechanisms help to lead the existence of newsworthiness in one part of the report successfully to the next one.

\subsection{News Discourse and Pragmatics}

Pragmatics deals with the way participants employ language to reflect contextual and social variables as well as to bring a change in the addressee's thinking. Thus, it is viewed of as concerned with potential meaning. In other words, it interprets how participants negotiate meaning in their interaction (Leech, 1983, p. 70; Morris, 1983, p. 6). Regarding PNRs, they can be seen as the product of the interaction between their producers and recipients. Hence, the meanings or values existing in this type of discourse represent the output of these participants. As Thomas (1995, p. 194) points out "pragmatic meaning is something which is constructed between speakers and hearers". In line with this perspective, pragmatics views language as a form of action or a way of doing things with words. Accordingly, actions such as promising, reporting and so on cannot be done without using words. In this regard, Montgomery $(2007$, p. 24) argues that such doings are the main characteristics of news discourse.

Consequently, the PMs such as presupposition, modality and deixis stand as the participants' appropriate tools to construct meanings or precisely NVs in this work. News reporters imply, suggest and so forth while recipients infer.

\subsection{Pragmatic Mechanisms}

\subsubsection{Presuppositions in News Reports}

Presupposition can be defined as the implicit meaning which is taken for granted. It is that kind of meaning which is assumed by speakers to be known by hearers. Moreover, this kind of meaning remains constant under negation. It is also argued that presupposions are important for their role to position hearers in a certain situation. Besides, they represent conditions which need to be satisfied before the utterance is issued felicitously to perform its function as a statement, a request etc. (Fascold, 1990, p. 166; Partee et al., 1996, p. 239; Hatim, 1997, p. 18; Malrieu, 1999, p. 95).

Presuppositions can be triggered by different types covering existential, factive, lexical, structural, non-factive and non-contextual presuppositions. The following sections introduce these types in some detail. 


\subsubsection{Existential Presuppositions (EPs)}

This type involves the indication of the existence of certain entities or things. Such presupposed meanings can be expressed by means of possessive constructions and definite noun phrases (Fairclough, 1995, pp. 6). The following example is illustrative in this regard:

John saw the man with two heads.

It presupposes the existence of a man with two heads (Levinson, 1983, p. 181).

\subsubsection{Factive Presuppositions (FPs)}

This kind can be expressed by utilizing verbs and expressions such as "regret, aware, realize, know, odd, be sorry that, be proud that, be indifferent that, be glad that, be sad that, etc". for example:

Martha regrets drinking John's home brew.

The verb "regret" presupposes that Martha drank John's home brew (ibid.).

\subsubsection{Lexical Presuppositions (LPs)}

In addition to the previous types, a number of expressions may be used to indicate what is called as "lexical presuppositions". In LPs, the speaker's use of a particular expression is taken to presuppose another concept whereas in FPs the use of a particular expression is taken to presuppose the truth of the information that is stated after it. Other lexical items such as "stop, start, again and so on" with their presuppositions are illustrated in the example below (Yule 1996, pp. 28):

You are late again.

The above example presupposes that "You were late before".

\subsubsection{Structural Presuppositions (SPs)}

In the case of SP, certain sentence structures have been analyzed as conventionally and regularly presupposing that part of the structure is already assumed to be true. Speakers may use such structures to treat information as presupposed (i.e., assumed to be true) and to be accepted as true by the listener. For example:

When did he leave?

This is interpreted with the presupposition that the information after the wh-form is already known to be the case.

\subsubsection{Non-factive Presuppositions (NPs)}

This type is one that is assumed not to be true. Triggers of this type include verbs like 'dream, imagine, pretend, etc., as shown in the following example (ibid., p. 29):

I dreamed that I was rich.

It presupposes "I was not rich".

\subsubsection{Counter-factual Presuppositions (CPs)}

The last type of presuppositions is that of counter-factual presupposition. One way of expressing this type is the use of conditional sentences as in the following example:

If Hannibal had only had twelve more elephants, the Romance languages would/would not this day exist.

This example presupposes that "Hannibal didn't have twelve more elephants" (ibid.).

\subsubsection{Modality in News Reports}

Modality is centrally concerned with the speaker's attitude towards the factuality or actualization of the situation expressed by the rest of the clause. Modality as a pragmatic mechanism involves notions like un/necessity, reliability, obligation, certainty, likelihood and so forth (Griffiths, 2006, p. 110). Mainly, there are two types of modality including deontic and epistemic (henceforth DM \& EM respectively). NVs have to do with deontic and dynamic modality or modulation. Modality relates to the use of modal verbs, nouns, adjectives, or adverbs and other linguistic items that express evaluations of what is (not) necessary. Besides, it is concerned with reliability, certainty, confidence and likelihood. For Givon (1993, p. 172), modality may involve either an epistemic sense of lower certainty or lower probability, or various evaluative- also called "deontic"- senses of either ability, intent, preference, obligation, necessity or permission. According to Huddleston (2012, p. 173), modality can be expressed by different expressions including "possible, necessary, likely, probable, bound, insist, require, 
permission, possibility, must, should, can, may etc." Modality has to do with responding to the interpersonal function; namely, whether the text producer performs the function of informing or evaluating.

\subsubsection{Deontic Modality}

It concerns expressing the speaker's attitudes of obligation, permission or in between (Prodan, 1998: 71). For Huddleston (2012, pp. 178), DM deals with the speaker's attitude to the actualizations of future situations. Thus, it is a matter of imposing obligation or prohibition, granting permission and the like.

\subsubsection{Epistemic Modality}

As regards EM, it indicates conclusions about a variety of possibilities for what is the case in reality. It encodes the news reporters' boundaries of knowledge (Prodan, 1998, pp. 69-70). For Huddleston (2012, p. 178), this kind of modality deals with qualifications concerning the speaker's knowledge. It is associated with the speaker's attitude to the factuality of past or present time situations.

\subsubsection{Deixis in News Reports}

Deixis concerns the way of grammaticalizing characteristics of the context of the utterance and thus it involves the methods of uttering utterances. However, the significance of deixis lies in showing the meanings that are expressed by speakers to enable hearers to understand the text. Put another way, deixis refers to the phenomenon wherein understanding the meaning of certain words and phrases in an utterance requires contextual information (Lyons, 1977, p. 724; Levinson, 1983, p. 54). Generally, there are different types of deixis which include personal, spatial , temporal as shown in the following section.

\subsubsection{Personal Deixis}

Personal deixis (henceforth PD) involves identifying the grammatical persons utilized to refer to participants in the utterance. Thus, it covers the speaker, hearer and even over-hearers, those who are not directly addressed by the utterance. Such expressions include "this, that, these, those, I, we, you, she, he, her, him, etc." (Levinson, 1997, pp. 54-96).

\subsubsection{Spatial Deixis}

This type of deictic expressions refers to the location of the event in question. The most common spatial expressions (henceforth SD) are adverbs like 'here, there', and prepositions such as 'in, on, at' (Buhler, 2011, pp. $67)$.

\subsubsection{Temporal Deixis}

In addition to the aforementioned types, expressions of time, or temporal deixis (henceforth TD) also plays a deictic role. It identifies reference to time and the most frequent expressions of this type are adverbs like "now, then, last year, etc.", and prepositions like "in, at, etc." (Yule, 1996, p. 11).

\section{Method}

\subsection{The Eclectic Model of Analysis}

Pulling the previous notions and information together with observations made by this study leads to the development of an eclectic model for analyzing the selected data. This model encompasses three levels: news report structure, pragmatic mechanisms, and news values (newsworthiness). What follows summarizes this eclectic model.

\subsubsection{News Report Structure}

The structure of the PNR consists of three parts including HS, LS and DS.

\subsubsection{Headline Stage}

It is the first part of the PNR which initiates newsworthiness (See 2.5.1).

\subsubsection{Lead Stage}

As indicated earlier (See 2.5.2), this part constructs the newsworthiness triggered in the HS by providing more information about the event in question.

\subsubsection{Development Stage}

This is the last part of the news report which increases maximally the newsworthiness of the PNR (See 2.5.3). In other words, it gives more details about the event that is initiated the HS and constructed in the LS. 


\subsubsection{Pragmatic Mechanisms}

Such PMs cover those of initiation in the HS, construction in the LS and maximization in the DS newsworthiness of the events. Below are the PMs expected to be used in PNRs including:

\subsubsection{Presupposition}

As regards this PM, it may be triggered by means of existential, structural, lexical, factive, non-factive, and counter-factual presupposition (See 2.7.1.1, 2.7.1.2, 2.7.1.3, 2.7.1.4, 2.7.1.5 and 2.7.1.6 respectively).

\subsubsection{Modality}

As far as modality is concerned, two main markers are expected to be used by political news reporters including: deontic modality or epistemic modality (See 8.2.1 and 8.2.2 respectively).

\subsubsection{Deixis}

Finally, this PM involves three types covering personal, spatial, and temporal deixis (See 8.3.1, 8.3.2 and 8.3.3 respectively). Reporters may employ these types to initiate, construct or maximize newsworthiness.

\subsubsection{Newsworthiness Values}

This level of the eclectic model consists of NVs that are expected to be created by means of the PMs (See 2.3 above). All these NVs together will lead to reporters' ultimate goal, newsworthiness. Such standards of newsworthiness are distributed across the different parts of the PNR. These values contain the following ones: (1) negativity, (2) impact, (3) timeliness and (4) proximity (See 2.3.1, 2.3.2, 2.3.3 and 2.3.4 respectively). Figure 1 below summarizes the three levels of the model:

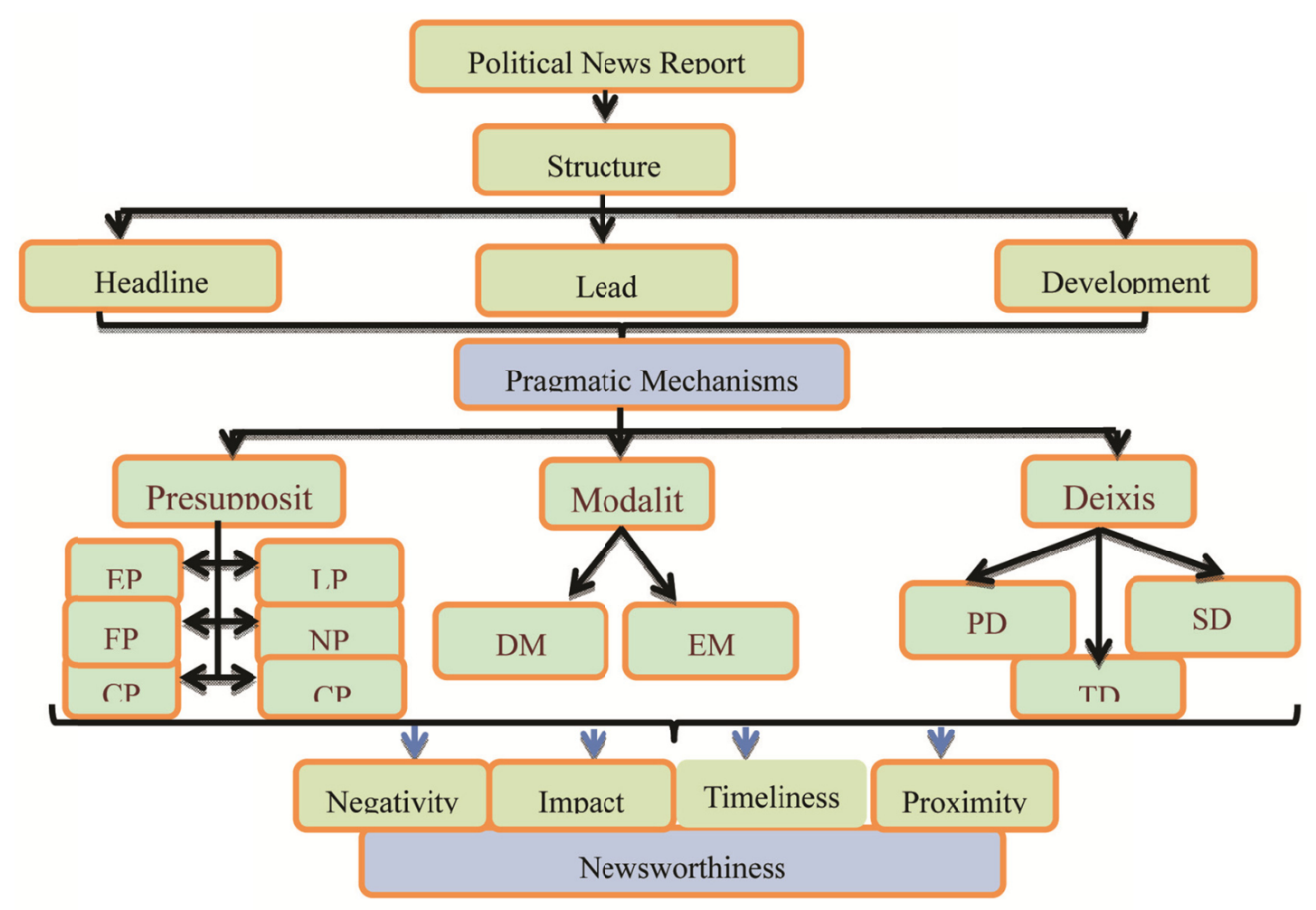

Figure 1. The eclectic model of analyzing PNRs

Note. $\mathrm{EP}=$ existential presupposition, $\mathrm{LP}=$ lexical presupposition, $\mathrm{FP}=$ Factive presupposition, $\mathrm{NP}=$ non-factive presupposition, $\mathrm{CP}=$ counter presupposition, $\mathrm{NCP}=$ non-counter presupposition, $\mathrm{DM}=$ deontic modality, $\mathrm{EM}=$ epistemic modality, $\mathrm{PD}=$ personal deixis, $\mathrm{TD}=$ temporal deixis, $\mathrm{SD}=$ spatial deixis.

The data under scrutiny consist of two PNRs broadcasted by CNN News Satellite Channel. They are concerned with the American presidential electoral campaigns, specifically, those of Trump's, the Republican nominee, speeches against his Democratic rival, Hillary Clinton, and the American president Barak Obama. 
The analysis of the collected data involves three steps. First, an analysis of the NVs as well as the PMs used to create these values is carried out. Second, a statistical analysis of the frequency of the PMs in the three parts of the PNR is employed. Third, a pragmatic analysis of some representative examples will be given. However, the percentage equation will be used to calculate the findings of the analysis. The symbols used in the analysis:

$\mathrm{R} 1=$ report two

$\mathrm{R} 2=$ report one

\section{Results}

\subsection{Analysis of Newsworthiness and PM in PNRs}

As indicated earlier 2.3, newsworthiness is mediated through language. Phrased differently, newsworthiness is constructed by means of discourse, precisely via PMs. Thus, the following sections shed light on the analysis of such PMs and NVs in the data under scrutiny depending on the developed model earlier 3.1.

The analysis shows that CNN news reporters adopt the NV of "negativity" to initiate (HS), construct (LS) and maximize (DS) newsworthiness of the events in question. It receives the highest frequency $50 \%$. Concerning the PMs used to issue this NV, it is issued by means of triggers of presupposition. No use of deixis or modality has been observed to issue this NV.

Regarding the NV of "impact", its use, although is employed less than that of "negativity", is remarkably observed in the collected data. It is used highly in the three parts of PNRs. As with "negativity", CNN news reporters utilize it in the initiation stage HS, in the construction stage LS and in the maximizing stage DS. For the sake of triggering this NV, CNN news reporters rely on the PMs of presupposion and modality. Differently put, in the HS, it is launched by the PM of presupposion, in the LS, the PMs of presupposition and modality are used whereas in the DS, it is conveyed via presupposition and modality. It total frequency amounts to $33.333 \%$.

In addition to the aforementioned NVs, it seems effective for CNN news reporters to use the NV of "timeliness". The analysis reveals its employment in the two stages of creating newsworthiness: LS and DS. As far as the PMs of issuing this NV, it is launched by means of "deixis". On the contrary, no use has been made of presupposition or modality to take part in this regard. The frequency of this NV amounts to $13.333 \%$.

Finally, the NV of 'proximity' appears a subsidiary one to create newsworthiness of political events. In this regard, the analysis reveals that it is used only in DS to maximize the event in question with the frequency $6.666 \%$. Together, these findings, as listed in Tables (1 and 2$)$ and schematized in Figures (2 and 3$)$ below, partly fulfill aim 2 and verify hypothesis 2 :

Table 1. Pragmatic mechanisms \& news values in PNRs

\begin{tabular}{ll}
\hline & HS \\
\hline Pragmatic Mechanism & News Value \\
Presupposition & Negativity, Impact \\
Modality & No Value \\
LS & No Value \\
Presupposition & \\
Modality & Negativity, Impact \\
Deixis & Negativity, Impact \\
DS & Negativity, Timeliness \\
Presupposition & \\
Modality & Negativity, Impact \\
Deixis & Negativity, Impact \\
\hline
\end{tabular}

Note. HS=headline stage, $\mathrm{LS}=$ lead stage, $\mathrm{DS}=$ developing stage.

Table 2. Frequency of news values in PNRs

\begin{tabular}{lllll}
\hline Stage & News Values & & & \\
\hline & negativity & impact & timeliness & proximity \\
Initiating & $6.666 \%$ & $6.666 \%$ & $0 \%$ & $0 \%$ \\
Constructing & $20 \%$ & $13.333 \%$ & $6.666 \%$ & $0 \%$ \\
Maximizing & $20 \%$ & $13.333 \%$ & $6.666 \%$ & $6.666 \%$ \\
Total & $46.666 \%$ & $33.333 \%$ & $13.333 \%$ & $\mathbf{6 . 6 6 6 \%}$ \\
\hline
\end{tabular}




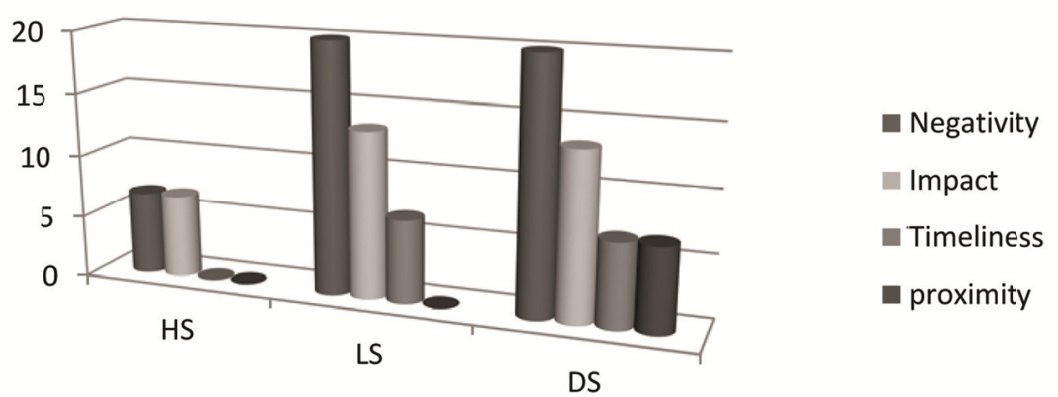

Figure 2. News values in the different stages of PNRs

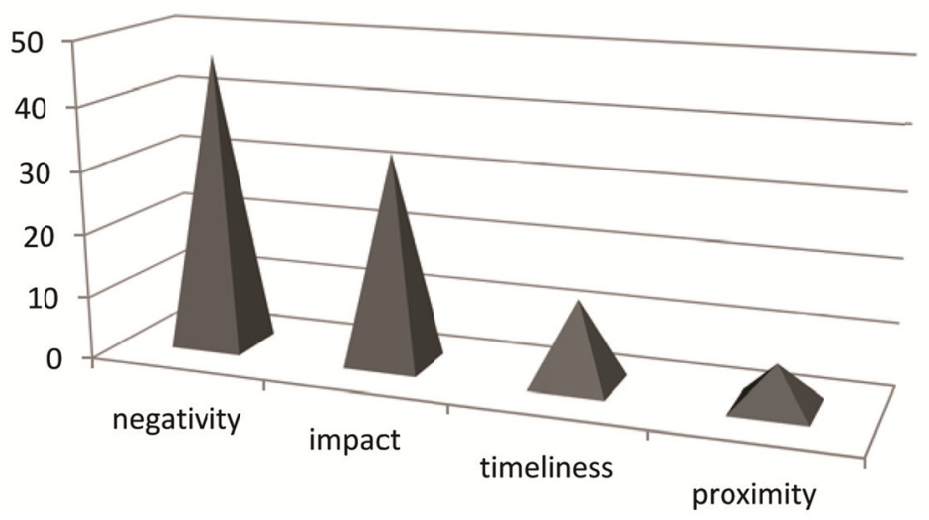

Figure 3. Frequency of news values in PNRs

\subsection{Statistical Analysis of PMs in PNRs}

Generally, three main PMs are utilized by CNN news reporters to create newsworthiness of the selected events including presupposition, modality and deixis. As Table 3 below shows, they are used (88) times across the three parts of the reports. These findings are schematized in Figure 4:

Table 3. Use \& Frequency of PMs in PRs

\begin{tabular}{|c|c|c|c|c|c|c|c|}
\hline \multirow[t]{3}{*}{ PM } & \multicolumn{6}{|l|}{ RS } & \multirow[t]{3}{*}{ Total } \\
\hline & \multicolumn{3}{|l|}{$\mathrm{R} 1$} & \multicolumn{3}{|l|}{ R2 } & \\
\hline & HS & LS & DS & HS & LS & DS & \\
\hline Presupposition & 1 & 3 & 8 & 1 & 1 & 7 & $\begin{array}{l}21 \\
(23.863 \%)\end{array}$ \\
\hline Modality & 0 & 1 & 2 & 0 & 0 & 14 & $\begin{array}{l}17 \\
(19.318 \%)\end{array}$ \\
\hline Deixis & 0 & 3 & 9 & $\mathbf{0}$ & 3 & 35 & $\begin{array}{l}50 \\
(56.818 \%)\end{array}$ \\
\hline Total & 1 & 7 & 19 & 1 & 4 & 57 & 88 \\
\hline
\end{tabular}




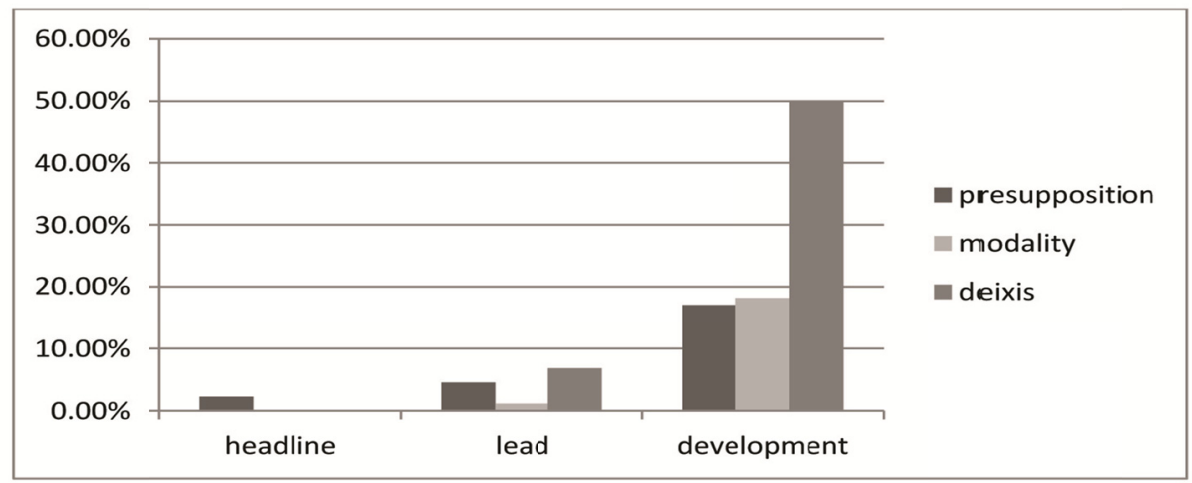

Figure 4. PMs in PNRs

\section{A. PMs in HS}

As regards the HS, the analysis reveals that presupposition is the most frequently used PM in all reports amounting to $100 \%$. In R1, it is triggered by SP amounting to $1.136 \%$ and R2 by EP which has amounted to $1.136 \%$. Concerning both modality and deixis, no use has been observed in the collected data. The findings of this analysis are mentioned in Table 4, and sketched in Figure 5 below. Together, they partly fulfill the aims 1 and 3 and at the same time verify hypothesis 3 and partly 5 :

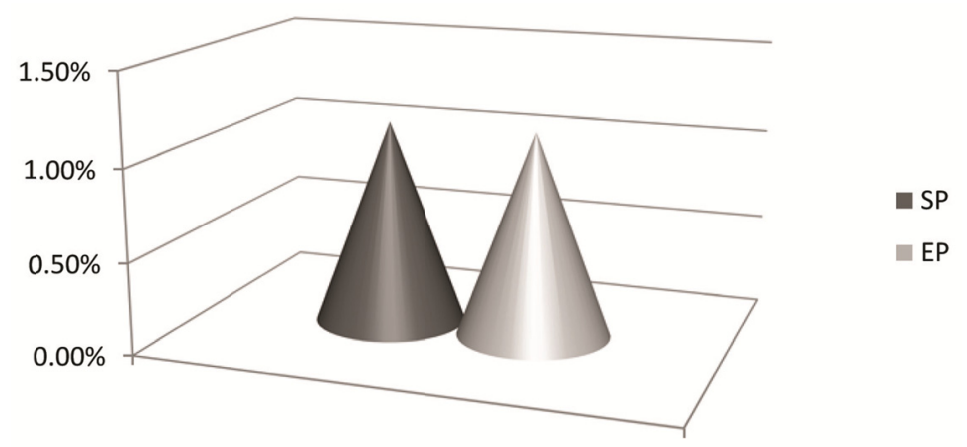

Figure 5. PMs in HS

\section{B. PMs in LS}

As far as the LS is concerned, CNN reporters utilize the PMs of presupposition, modality and deixis to construct newsworthiness of the events in question. In this regard, the PM of deixis has the highest percentage $6.818 \%$. In $\mathrm{R} 1$, reporters employ TD amounting to $2.272 \%$ and $\mathrm{PD}$ amounting to $1.136 \%$. In R2, also two types of deictic expressions are utilized: PD having the percentage $2.272 \%$ and TD $1.136 \%$. The second ranked PM used by CNN reporters in this stage is presupposition with frequency of use amounting to $4.545 \%$. In R1, it is triggered by LP $2.272 \%$ and FP $1.136 \%$, in R2 by LP $1.136 \%$. Lastly, the PM of modality, precisely EM, comes last with the percentage $1.136 \%$ since it is used only in R1 by means of EM amounting to1.136\%. The findings of this analysis are mentioned in Table 4, and sketched in Figure 6 below. These findings fulfill the aims 1 and 3 and verify pertly hypothesis 3 : 


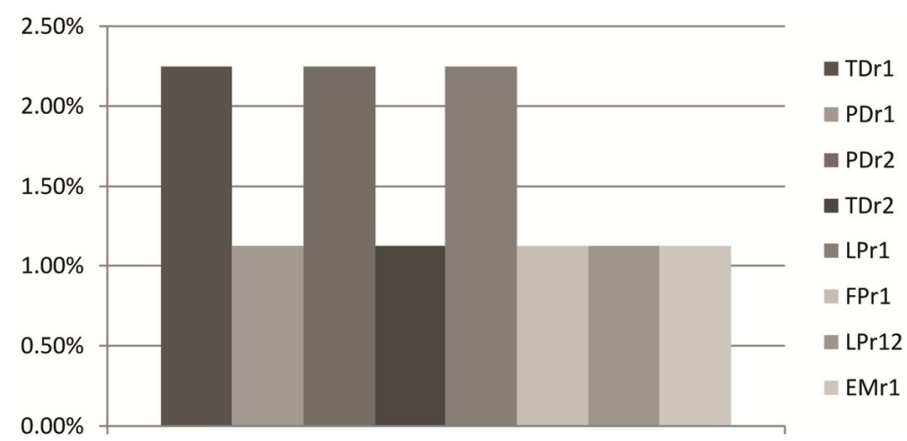

Figure 6. PMs in LS

Note. $\mathrm{r} 1=$ report one, $\mathrm{r} 2=$ report two.

\section{PMs in DS}

Finally, the analysis reveals that the last stage of PNRs, DS, is carried out by means of the PMs of deixis which occupies the first rank 50\%, modality $18.181 \%$ and then presupposition $17.045 \%$. For deixis, in R1, it is issued by PD $6.818 \%$ and TD $3.409 \%$; in R2 by PD $26.136 \%$ and TD $6.818 \%$ and SD $6.818 \%$. Concerning modality, in $\mathrm{R} 1$, it is expressed by EM amounting to $3.409 \%$ while in R2 amounting to $15.909 \%$. As regards presupposition, in R1, the triggers used are LP $3.370 \%$, FP $3.409 \%$ and EP $2.272 \%$; in R2 are EP 3.409\%, LP $2.272 \%$ and SP $2.272 \%$. Together, they partly fulfill the aims 1 and 2 and verify hypothesis 5 whereas rejects hypothesis 6 . These findings are listed in Table 4 and schematized in Figure 7:

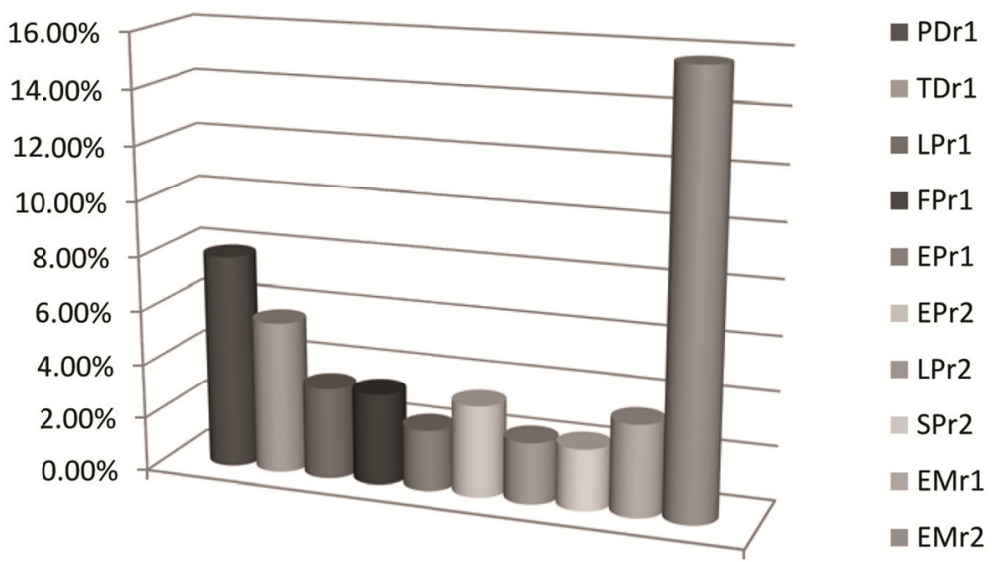

Figure 7. PMs in DS

Table 4. Use \& frequency of PMs in PNRs

\begin{tabular}{|c|c|c|c|c|c|c|c|}
\hline \multirow[t]{2}{*}{ PM } & \multicolumn{3}{|l|}{ R1 } & \multicolumn{3}{|l|}{ R2 } & \multirow[t]{2}{*}{ Total } \\
\hline & $\mathrm{H}$ & $\mathrm{L}$ & $\mathrm{D}$ & $\mathrm{H}$ & $\mathrm{L}$ & $\mathrm{D}$ & \\
\hline EP & 0 & 0 & $\begin{array}{l}2 \\
(2.272 \%)\end{array}$ & $\begin{array}{l}1 \\
(1.136 \%)\end{array}$ & 0 & $\begin{array}{l}3 \\
(3.409 \%)\end{array}$ & 6 \\
\hline $\mathbf{L P}$ & 0 & $\begin{array}{l}2 \\
(2.272 \%)\end{array}$ & $\begin{array}{l}3 \\
(3.409 \%)\end{array}$ & 0 & $\begin{array}{l}1 \\
(1.136 \%)\end{array}$ & $\begin{array}{l}2 \\
(2.272 \%)\end{array}$ & 8 \\
\hline $\mathbf{F P}$ & 0 & $\begin{array}{l}1 \\
(1.136 \%)\end{array}$ & $\begin{array}{l}3 \\
(3.409 \%)\end{array}$ & 0 & 0 & 0 & 4 \\
\hline NP & 0 & 0 & 0 & 0 & 0 & 0 & 0 \\
\hline SP & $\begin{array}{l}1 \\
(1.136 \%)\end{array}$ & 0 & 0 & 0 & 0 & $\begin{array}{l}2 \\
(2.272 \%)\end{array}$ & 3 \\
\hline $\mathrm{CP}$ & 0 & 0 & 0 & 0 & 0 & 0 & 0 \\
\hline DM & 0 & 0 & 0 & 0 & 0 & 0 & 0 \\
\hline EM & 0 & $\begin{array}{l}1 \\
(1.136 \%)\end{array}$ & $\begin{array}{l}2 \\
(2.272 \%) \\
\end{array}$ & 0 & 0 & $\begin{array}{l}14 \\
(15.909 \%)\end{array}$ & 17 \\
\hline
\end{tabular}




\begin{tabular}{|c|c|c|c|c|c|c|c|}
\hline PD & 0 & $\begin{array}{l}1 \\
(1.136 \%)\end{array}$ & $\begin{array}{l}6 \\
(6.818 \%)\end{array}$ & 0 & $\begin{array}{l}2 \\
(2.272 \%)\end{array}$ & $\begin{array}{l}23 \\
(25.842 \%)\end{array}$ & 32 \\
\hline TD & 0 & $\begin{array}{l}2 \\
(2.272 \%)\end{array}$ & $\begin{array}{l}3 \\
(3.409 \%)\end{array}$ & 0 & $\begin{array}{l}1 \\
(1.136 \%)\end{array}$ & $\begin{array}{l}6 \\
(6.818 \%)\end{array}$ & 12 \\
\hline SD & 0 & 0 & 0 & 0 & 0 & $\begin{array}{l}6 \\
(6.818 \%)\end{array}$ & 6 \\
\hline Total & $\begin{array}{l}1 \\
(1.136 \%)\end{array}$ & $\begin{array}{l}7 \\
(7.954 \%)\end{array}$ & $\begin{array}{l}20 \\
(21.590 \%)\end{array}$ & $\begin{array}{l}1 \\
(1.136 \%)\end{array}$ & $\begin{array}{l}4 \\
(4.545 \%) \\
\end{array}$ & $\begin{array}{l}56 \\
(63.636 \%)\end{array}$ & $\begin{array}{l}88 \\
(100 \%) \\
\end{array}$ \\
\hline
\end{tabular}

\section{Discussion}

\subsection{Presupposition}

According to the statistical analysis, the PM of presupposition plays an important role in initiating, constructing and maximizing newsworthiness involved in the collected data (Table 3). For instance, in R1, to fulfill this purpose, CNN reporters make use of three triggers including SP, LP and FP:

Donald Trump tries to walk back claim Obama founded ISIS,... the widely criticized false claim he repeatedly made,...the tweet was the first move by Trump to moderate his comments, which he had repeated multiple times since he featured them ... that Trump's claim was false, ...his boss would have to speak for himself on the issue of Obama and ISIS, ... that Trump's claim was false,

In these extracts, the PMs of SP in the HS, LP in both LS and DS, and EP in the DS are used to initiate in the HS, construct in the LS, and maximize in the DS the newsworthiness of the event in question via issuing the NVs of "negativity and impact" (Tables 1 and 2). Concerning HS, the reporter initiates the newsworthiness, creating negativity and impact, by presupposing via SP that Trump claims that "Donald Trump tries to walk back claim Obama founded ISIS" (8.1.4). Other cases of SP are (15 and 17) in Appendix A. This initiation has been reinforced in LS where the reporter employed the MP of LP (8.1.3) presupposing lexically by using the adverb "repeatedly" that Trump's claim is not new, but had taken place in the past. This PM is utilized here to construct the NVs of "negativity and impact" (Tables 1 and 2). Such uses of LP are $(3,4,10,12,13,16$ and 21) in Appendix A. Moreover, these two stages are maximized in the DS through employing EP (8.1.1), FP (See 8.1.2) and LP with aim of maximizing the NVs of "negativity and impact" (See Tables 1 and 2). Thus, the phrase "repeated multiple times" shows that the co-occurrence of Trump's claim, the verb "featured" presupposes factively "Trump's claim", and the possessive -s presupposes the existence of this claim. Such uses of EP are $(8,14,18,19$ and 20) in Appendix A while other occurrences of FP are (7,9 and 11) in Appendix A.

\subsection{Modality}

Concerning modality, the analysis reveals that this PM has been utilized to construct as well as maximize the newsworthiness, NVs of negativity and impact, of the events in question (See Tables 1 and 2). For instance, in $\mathrm{R} 2$, the CNN reporter relies heavily on this mechanism to maximize the newsworthiness of Trump's attack against the Democratic nominee's (Clinton) character. The following extracts illustrate:

"Unstable Hillary Clinton, lacks the judgment, temperament and moral character to lead this country and I believe that so strongly," Trump told supporters as he accused Clinton of supporting policies..., Trump told supporters as he accused Clinton of supporting policies that he said could damage US national security..., Several Trump supporters responded more aggressively to Trump's biting excoriation of Clinton's character.

After imitating the newsworthiness of Trump's attack in the HS and the constructed in the LS (Appendix B), different markers of modality are used to maximize the NVs of "negativity and impact" in the DS. As these texts show, the reporter uses main verbs, verbs of certainty, such as "told, say" to covey certainty of Trump's negative attack (8.2 and 8.2.2). In other words, the reporter asserts for audience Trump's offensive attacks. Other uses of main verbs expressing EM are (25,27,28,29,30,32,34,35,36,37 and 38) Appendix B. Besides, modal verb are also employed to maximize NVs of "negativity and impact". Such verbs involve "could" expressing a lower degree of certainty of Clinton's future effects on USA policies. Similar cases of modal verbs are (24,26 and 33) in Appendix B. In addition, adverbs of EM are utilized maximizing Trump's offensive attack, that is, the adverb "more aggressively" clarifies that Trump's attacks lead his supporters to behave more unfriendly against Clinton's character. Such other examples of EM adverbs are (22 and 23) in Appendix B. 


\subsection{Deixis}

As far as the PM of deixis is concerned, it is employed by CNN reporters to construct as well as maximize newsworthiness of the events, precisely the NVs of "negativity and timeliness" (Tables 1 and 2). To be more clarified, R1 and R2 involve some deictic expressions to achieve these purposes:

Donald Trump on Friday attempted to walk back the widely criticized false claim he repeatedly made over the last two days that President Barack Obama and Hillary Clinton were "co-founders" of ISIS..., Trump's attorney Michael Cohen told CNN's Chris Cuomo on "New Day" on Friday that his boss..., In an interview Trump did...on Thursday morning...get Trump to say he was being metaphorical or hyperbolic, Trump repeatedly refused....

R2

The Republican nominee, speaking in Des Moines, Iowa, accused Clinton..., Trump pressed forward with his attacks on Clinton's character... in Green Bay, Wisconsin.

In the above cited texts, following the developed model, the analysis reveals these texts include PD, TD and SD. As regards PD (2.7.3), these expressions are mainly utilized in both LS and DS. For instance, on the one hand, the personal pronoun "he" is used twice, conveying the NV of "negativity", in LS, R1 above, to mention repeatedly the agent of the offensive claim, Trump. On the other hand, the same pronoun is employed by the reporter in DS of the same report to maximize the newsworthiness, negativity, of this event, Trump's claim, again by referring to the agent of this offensive claim. It is worth mentioning that such use of this PM is utilized in $(39,40,41,42,43,45,51,52,53,54,55,56,57,58,59.60,61,62,63,64,65,66,67, \quad 8,69,70,71,72,73,74$ and 75$)$ (Appendix C).

As regards TD, the texts contain some temporal expressions (2.7.3) in LS constructing the newsworthiness, expressing the NV of "timeliness", of Trump's claim in R1 by referring to the time of issuing his claims (Tables 1 and 2). Put it another way, the reporter makes clear when Trump's offensive claims have happened. Besides, these deictic expressions how close temporally this event to the time of broadcasting this event. Similar uses of such PM are $(46,47,48,49,50,76,77,78,79,80,81$ and 82$)$ in Appendix C.

Finally, the PM of SD is being subject to CNN reporters. According to the model advanced earlier (2.7.3), the texts above, DS of R2, include some spatial expressions, expressing the NV of "proximity" (Tables 1 and 2). Their main task is to maximize the places of Trump's attack against Clinton. Phrased differently, these deictic expressions maximize the event by means of referring to the locations in which Trump declares his claims. Such a use inspires an idea about the influence of these attacks on those living in these places, and thus, their decisions about the best candidate might be affected. Other situations of this PM are $(83,84,85,86,87$ and 88$)$ in Appendix C.

\section{Conclusions}

On the basis of the analysis and the discussion of the findings, the following conclusions can be introduced:

1). Newsworthiness is best created by utilizing PMs such as presupposition, modality and deixis. Accordingly, hypothesis 1 is validated.

2). Presupposition triggers are used to initiate, construct and maximize newsworthiness of PNRs. This conclusion verifies hypothesis 3 and partly 5 .

3). Both modality and deixis are utilized to construct and heavily used to maximize newsworthiness of PNRs. Accordingly, hypotheses $4 \& 5$ are partly valid.

4). The conclusions in 2 and 3 above verify hypothesis 5 since they prove that all PMs contribute to the development of newsworthiness in the DS.

5). The most frequent PM in the HS, initiating newsworthiness, is presupposition triggers while the most frequent PMs in the LS, constructing newsworthiness, are deixis and presupposition triggers and in the DS, maximizing newsworthiness, the most frequent PM are deixis and presupposition triggers. This validates partly hypothesis 6.

6). Certain presupposition triggers are not used by CNN reporters, DM is not used, and SD is rarely utilized.

7). Negativity and impact represent the most worthy NVs utilized by CNN reporters to create newsworthiness of the political events. Thus, hypothesis 2 is validated.

8). The model developed by this study appears efficient to analyze PNRs. 


\section{References}

Al-Duleimi, A., \& Al-Ebadi, H. (2016). Ideology in News Reports: Al-Jazeera Reporters as Representative: a Critical Discourse Analysis. British Journal of English Linguistics, 4(2), 53-66. Retrieved from www.eajournals.org

Al-Ebadi, H. (2012). A Systemic-Functional Analysis of Religious Texts with Reference to the Epistle of "James". Journal of Thiqar Arts, 2(7), 1-20.

Bednarek, M., \& Caple, H. (2012). News Discourse. London: Continuum International Publishing Group.

Bell, A. (1991). The Language of News Media. Oxford: Blackwell.

Bell, A. (1997). Language style as audience design. In N. Coupland \& A. Jaworski (Eds.), Sociolinguistics: A reader and coursebook (pp. 240-250). Basingstoke: Macmillan. https://doi.org/10.1007/978-1-349-25582-5_20

Buhler, K. (2011). Theory of Language. Amsterdam: John Benjamins Publishing Company. https://doi.org/10.1075/z.164

Conboy, M. (2002). The Press and Popular Culture. London: Sage.

Cotter, C. (2010). News Talk: Investigating the Language of Journalism. Cambridge: CUP. https://doi.org/10.1017/CBO9780511811975

Fairclough, N. (1995). Critical Discourse Analysis. London: Longman.

Fascold, R. (1990). The Sociolinguistics of Language. London: Basil Blackwell.

Feez, S., Iedema, R. \& White, R. (2008). Media Literacy. Surry Hills, NSW: NSW Adult Migrant Education Service.

Fowler, R. (1977). Linguistics and the Novel. London : Methuen.

Fowler, R. (1991). Language in the News: Discourse and Ideology in the Press. London: Routledge.

Givon, T. (1993). English Grammar: A Functional-Based Introduction. V2. Philadelphia: John Benjamins Publishing Company.

Griffiths, P. (2006). An Introduction to English Semantics and Pragmatics. Edinburgh: Edinburgh University Press.

Hatim, B. (1997). Communication across Culture. Exeter: University of Exeter Press.

Huddleston, R. (2012). "The Verb”. In R. Huddleston \& G. Pullum (Eds.), In the Cambridge Grammar of the English Language. Cambridge: Cambridge University Press.

Kress, G. (1989). Linguistic Process in Sociocultural Practice (2nd ed.). Oxford: Oxford University Press.

Levinson, S. (1983). Pragmatics. Cambridge: Cambridge University Press.

Levinson, S. (1997). Pragmatics. USA: Cambridge University Press.

Lyons, J. (1977). Deixis, space and time. Semantics, 2. Cambridge: Cambridge University Press.

Malrieu, J. (1999). Evaluative Semantics. Language Cognition and Ideology. New York: Routledge.

Morris, C. (1938). Foundation of the Theory of Signs. Chicago: University of Chicago Press.

Partee, H., \& Sgall, P. (Eds.). (1996). Discourse and Meaning. Amsterdam: John Benjamins. https://doi.org/10.1075/z.78

Prodan, L. (1998). Enacting a Community's Truth: The Pragmatics of Literary Gossip. Unpublished M.A. Thesis: Simson Frases University.

Rau, C. (2010). Dealing with the Media. Sydney: University of New South Wales Press.

Reah, D. (2002). The Language of Newspapers. London and New York: Routledge.

Richardson, E. (2007). Analysing Newspapers: An Approach from Critical Discourse Analysis. New York: Palgrave Macmillan. https://doi.org/10.1007/978-0-230-20968-8

Thomas, J. (1995). Meaning in Interaction: An Introduction to Pragmatics. London: Longman. 
Van Dijk, A. (1991). Media contents: The interdisciplinary study of news as discourse. In K. B. Jensen \& N. W. Jankowski (Eds.), A handbook of qualitative methodologies for mass communication research (pp. 108, 120). London: Routledge.

Van Dijk, T. (1988). News as Discourse. Hillsdale: Lawrence Erlbaum.

Yule, G. (1996). Pragmatics. Oxford: Oxford University Press.

\section{Appendix A}

\section{Presupposition}

\begin{tabular}{lllll}
\hline RP & No. & Text & R No. & PT \\
\hline H & 1 & Donald Trump tries to walk back claim Obama founded ISIS & 1 & SP \\
L & 2 & the widely criticized false claim he repeatedly made... & 1 & LP \\
D & 3 & the tweet was the first move by Trump to moderate his comments... & 1 & LP \\
D & 4 & which he had repeated multiple times... & 1 & LP \\
D & 5 & $\ldots$ since he featured them, & 1 & FP \\
D & 6 & that Trump's claim was false, & 1 & EP \\
D & 7 & Trump: I meant Obama founded ISIS & 1 & FP \\
D & 8 & ...his boss would have to speak for himself on the issue of Obama and ISIS, & 1 & EP \\
D & 9 & Trump had been insisting Obama was a founder of ISIS & 1 & FP \\
D & 10 & Trump repeatedly refused... & 1 & LP \\
L & 11 & Trump ... insisted he really meant Obama was a founder of ISIS & 1 & FP \\
L & 12 & Trump also repeated the comments at campaign events on Thursday. & 1 & LP \\
H & 13 & Trump escalates attacks on Clinton's character & 2 & LP \\
L & 14 & Donald Trump escalated his attacks Friday on Hillary Clinton's & 2 & EP \\
D & 15 & ...sought to amplify the controversies that have beset the Democrat's campaign. & 2 & SP \\
D & 16 & Repeatedly during his rally in Des Moines, Trump returned... & 2 & LP \\
D & 17 & Trump spent more of his time on the stump than at any rally in recent weeks attacking Clinton & 2 & SP \\
D & 18 & Trump pressed forward with his attacks on Clinton's character & 2 & EP \\
D & 19 & Trump's attacks on Clinton's character found their mark & 2 & EP \\
D & 20 & Trump's recent comments wavering on the strength of the US's commitment... & 2 & EP \\
D & 21 & While he spent much time attacking Clinton & 2 & LP \\
\hline
\end{tabular}

\section{Appendix B}

\section{Modality}

\begin{tabular}{|c|c|c|c|c|}
\hline $\mathbf{R P}$ & No. & Text & R No. & MM \\
\hline $\mathbf{L}$ & 22 & the widely criticized false claim... & 1 & EM \\
\hline D & 23 & he really meant Obama was a founder of ISIS. & 1 & EM \\
\hline $\mathbf{D}$ & 24 & his boss would have to speak for himself on the issue of Obama and ISIS & 1 & EM \\
\hline D & 25 & accused Clinton of being "unbalanced" and "unstable," called her... & 2 & EM \\
\hline D & 26 & a Clinton presidency would lead to "the destruction of this country from within." & 2 & EM \\
\hline D & 27 & "Unstable Hillary Clinton,..." Trump told supporters... & 2 & EM \\
\hline $\mathbf{D}$ & 28 & as he accused Clinton ... he said could damage US national security. & 2 & EM \\
\hline $\mathbf{D}$ & 29 & "The legacy of Hillary Clinton...," Trump said. "She's weak..." & 2 & EM \\
\hline D & 30 & "In one way she's a monster," Trump said. & 2 & EM \\
\hline $\mathbf{D}$ & 31 & Several...more aggressively to Trump's biting excoriation of Clinton's character. & 2 & EM \\
\hline $\mathbf{D}$ & 32 & “...unbalanced" and "unstable," called her & 2 & EM \\
\hline $\mathbf{D}$ & 33 & a Clinton presidency would lead to "the destruction of this country from within." & 2 & EM \\
\hline D & 34 & Trump told supporters as he accused & 2 & EM \\
\hline $\mathbf{D}$ & 35 & that he said could damage US national security & 2 & EM \\
\hline $\mathbf{D}$ & 36 & "The legacy of Hillary Clinton: ...," Trump said. & 2 & EM \\
\hline D & 37 & "In one way she's a monster," Trump said & 2 & EM \\
\hline D & 38 & "All my life, I have been told, 'You have the greatest temperament," Trump said & 2 & EM \\
\hline
\end{tabular}




\section{Appendix C}

Deixis

\begin{tabular}{|c|c|c|c|c|}
\hline RP & No. & Text & R No. & PT \\
\hline $\mathbf{L}$ & 39 & he repeatedly made & 1 & PD \\
\hline D & 40 & he featured them & 1 & PD \\
\hline D & 41 & his boss would have & 1 & PD \\
\hline D & 42 & I meant Obama founded ISIS & 1 & PD \\
\hline D & 43 & he was being metaphorical or hyperbolic & 1 & PD \\
\hline D & 44 & he really meant Obama was a founder of ISIS & 1 & PD \\
\hline D & 45 & After his interview with Hewitt, Trump also repeated the comments & 1 & PD \\
\hline $\mathbf{L}$ & 46 & on Friday & 1 & TD \\
\hline $\mathbf{L}$ & 47 & over the last two days & 1 & TD \\
\hline D & 48 & Wednesday night & 1 & TD \\
\hline $\mathbf{D}$ & 49 & For the last two days & 1 & TD \\
\hline D & 50 & on Thursday morning & 1 & TD \\
\hline $\mathbf{L}$ & 51 & his attacks Friday on Hillary Clinton's character... & 2 & PD \\
\hline $\mathbf{L}$ & 52 & just as top former government officials are questioning his own & 2 & PD \\
\hline D & 53 & "unbalanced" and "unstable," called her & 2 & PD \\
\hline D & 54 & After knocking himself off message & 2 & PD \\
\hline D & 55 & reading at times from prepared remarks on his podium & 2 & PD \\
\hline D & 56 & and I believe that so strongly & 2 & PD \\
\hline D & 57 & as he accused Clinton & 2 & PD \\
\hline D & 58 & he said could damage US national security & 2 & PD \\
\hline D & 59 & Repeatedly during his rally in Des Moines & 2 & PD \\
\hline D & 60 & those attacks with others on her policy positions & 2 & PD \\
\hline D & 61 & While he did not entirely abandon & 2 & PD \\
\hline D & 62 & While he did not entirely abandon & 2 & PD \\
\hline D & 63 & his signature style of jumping from one topic to the next. & 2 & PD \\
\hline $\mathbf{D}$ & 64 & ... he explained & 2 & PD \\
\hline D & 65 & his controversial comment about a crying baby at a recent rally-- & 2 & PD \\
\hline D & 66 & Trump spent more of his time on the stump than ... attacking Clinton & 2 & PD \\
\hline D & 67 & his attacks on Clinton's character & 2 & PD \\
\hline $\mathbf{D}$ & 68 & during his next stop ... & 2 & PD \\
\hline D & 69 & Trump's attacks on Clinton's character found their mark & 2 & PD \\
\hline D & 70 & with his supporters in Des Moines, & 2 & PD \\
\hline D & 71 & he agreed with the chants. & 2 & PD \\
\hline $\mathbf{D}$ & 72 & he himself faced stinging criticism from top US officials & 2 & PD \\
\hline D & 73 & While he spent much time attacking Clinton, & 2 & PD \\
\hline D & 74 & the real estate mogul and GOP nominee also defended himself & 2 & PD \\
\hline D & 75 & from accusations against his own character. & 2 & PD \\
\hline $\mathbf{L}$ & 76 & attacks Friday on Hillary Clinton's & 2 & TD \\
\hline D & 77 & during his next stop Friday night & 2 & TD \\
\hline D & 78 & at any rally in recent weeks attacking Clinton & 2 & TD \\
\hline D & 79 & --just over a week after he rejected & 2 & TD \\
\hline $\mathbf{D}$ & 80 & the Trump campaign Friday afternoon was not immediately returned. & 2 & TD \\
\hline D & 81 & on Friday & 2 & TD \\
\hline D & 82 & Trump said Friday in Des Moines & 2 & TD \\
\hline D & 83 & speaking in Des Moines, Iowa, accused Clinton & 2 & SD \\
\hline D & 84 & in this swing state that a Clinton presidency & 2 & SD \\
\hline $\mathbf{D}$ & 85 & Repeatedly during his rally in Des Moines & 2 & SD \\
\hline D & 86 & Trump pressed forward with his attacks...during his next stop in Green Bay, Wisconsin. & 2 & SD \\
\hline D & 87 & Trump's attacks ... found their mark with his supporters in Des Moines & 2 & SD \\
\hline D & 88 & Trump said Friday in Des Moines. & 2 & SD \\
\hline
\end{tabular}

\section{Copyrights}

Copyright for this article is retained by the author(s), with first publication rights granted to the journal.

This is an open-access article distributed under the terms and conditions of the Creative Commons Attribution license (http://creativecommons.org/licenses/by/4.0/). 